\title{
O fluxo migratório brasileiro em Orlando e o papel das igrejas brasileiras: uma pesquisa em andamento
}

\author{
The brazilian migratory flow in Orlando and the role of brazilian churches: an \\ ongoing research
}

\author{
Kelly Thaysy Lopes Nascimento*
}

\begin{abstract}
Resumo
Concluímos dados que confirmam a presença de imigrantes brasileiros em igrejas a partir de 1992 na cidade de Orlando. As entrevistas revelam que há uma primeira geração de brasileiros na década de 1990 na cidade central da Flórida e sua participação em igrejas americanas, pois não havia igrejas brasileiras. A primeira igreja brasileira que se constituiu em Orlando chama-se Primeira Igreja Brasileira Batista de Orlando (1998), conhecida popularmente pela sigla PIBBO e a Igreja Católica constituiu sua primeira paróquia para brasileiros em (2002) com a Ressurection Catholic Church. Esta pesquisa pretende contribuir com dados sobre o papel da igreja brasileira para imigrantes brasileiros em Orlando, neste momento inserimos os primeiros dados sobre o fluxo migratório brasileiro, esta coleta se encontra em andamento e conta com métodos exploratórios através de entrevistas, observação participante e survey na plataforma MonkeySurvey. Conta com apoio produtividade CAPES.
\end{abstract}

Palavras-chave: Fluxo migratório; imigrantes brasileiros; igrejas brasileiras; Flórida Central.

\begin{abstract}
We conclude data on the presence of Brazilian immigrants in churches since 1992 in the city of Orlando. The interviews reveal that there is a first generation of Brazilians in the 1990s in the central city of Florida and their participation in American churches, since there were no Brazilian churches. The first Brazilian church to be constituted in Orlando is called First Baptist Church of Orlando (1998), popularly known by the acronym PIBBO and the Catholic Church constituted its first parish for Brazilians in (2002) with Ressurection Catholic Church. This research intends to contribute with data on the role of the Brazilian church for Brazilian immigrants in Orlando, at this moment we insert the first data about the Brazilian migratory flow, this collection is in progress and has exploratory methods through interviews, participant observation and survey in the MonkeySurvey platform. Features CAPES productivity support.
\end{abstract}

Keywords: Migratory flow; brazilian immigrants; brazilian churches; Central Florida.

Comunicação submetida em 02 de julho de 2019 e aprovada em 30 de agosto de 2019.

*Doutoranda em Ciências da Religião no Programa de Pós-graduação em Ciências da Religião da UFPB. País de origem: Brasil. E-mail: thaysy.lopes@gmail.com

Horizonte, Belo Horizonte, v. 17, n. 53, p. 1315-1332, maio/ago. 2019 - ISSN 2175-5841 


\section{Introdução}

Na década de 1980, uma geração de brasileiros emigrou para os Estados Unidos e é conhecida como "imigrantes da primeira geração". Destaque-se que as primeiras pesquisas sociológicas e antropológicas buscaram identificar a razão e perfil do fluxo migratório e os primeiros estudos exploratórios ocorreram em Massachusetts e Nova York.

No primeiro campo, feito por uma brasileira, Ana Cristina Martes (1992), e no segundo, por uma americana, Maxine Margolis (1994), as pesquisas identificaram que, na primeira geração migratória, há um êxodo da condição econômica que se estabelecia com a crise política; uma segunda geração se constituiu e as pesquisas identificaram também o êxodo da violência, visto que muitos brasileiros emigraram para os Estados Unidos com o objetivo de segurança e qualidade de vida.

Percebemos nessas primeiras pesquisas uma singularidade: a participação das igrejas no apoio aos brasileiros que se situaram no novo país, pois muitas instituições religiosas brasileiras estão surgindo nos Estados Unidos com o objetivo de alcançar os imigrantes brasileiros. Identificamos, pois, que os espaços religiosos promovem a transnacionalização e desenvolvem assistência social específica aos imigrantes; há, dessa forma, uma reconfiguração religiosa, uma modernização nas práticas de recrutamento.

Devido à escassez de pesquisas em relação ao tema ora desenvolvido, optamos por explorar um campo migratório com quantidade expressiva de sujeitos brasileiros. Portanto, o objetivo dessa pesquisa é, por meio dos dados qualitativos e quantitativos, identificar o perfil migratório atual na Flórida Central - Orlando - e o papel das igrejas brasileiras nas práticas de recrutamento dos imigrantes brasileiros. Metodologicamente, contamos com o apoio de entrevistas estruturadas e não estruturadas, da observação participante, bem como com um survey de perfil sociodemográfico na plataforma MonkeySurvey. 
Percebemos a importância dos trabalhos sociológicos e antropológicos para os debates sobre o fluxo migratório e entendemos a necessidade da pesquisa da(s) Ciência(s) da(s) Religião(ões) para abordar o tema da igreja brasileira da diáspora. Os dados contribuem com os estudos sobre a realidade migratória, fornecendo novos dados acadêmicos e debates interdisciplinares, como também se inserem com importante função informacional à sociedade, principalmente concernente à parcela populacional que se determina à migração.

Esta pesquisa ${ }^{1}$, na área $\mathrm{da}(\mathrm{s})$ Ciência(s) da(s) Religião(ões), pretende contribuir com o debate e se inserir como disciplina essencial à pesquisa da diáspora brasileira nos Estados Unidos. Ressaltamos a importância do apoio produtividade da CAPES, o qual viabiliza a internacionalização da pesquisa e indicamos que os resultados para este tema são possíveis, sobretudo pela diversificação metodológica própria das Ciências humanas.

\section{0 fluxo migratório brasileiro em Orlando}

O Estado tecnológico ${ }^{2}$ estabelece um novo modo de constituição social e forma o advento das transformações. Obtêm-se a necessidade de um sistema político adequado à estrutura tecnológica que estabelece globalmente o advento informacional. $\mathrm{O}$ acesso à informação global gera o conhecimento, bem como o compartilhamento das falhas no sistema político, e a sociedade promove em atos de mobilização o êxodo da corrupção. Enquanto parte da população brasileira que sente as transformações e crises políticas encontra no fluxo migratório o seu êxodo da crise econômica, outra se insere como sujeito da modernidade em meio à crise para estabelecer como sujeito federativo o alcance do sistema político incorruptível.

As transformações ocorridas no campo político, graças à Revolução Francesa, e na economia, graças às inovações tecnológicas que criam uma nova divisão de trabalho e novas classes sociais, fundam as bases de possibilidades para profundas alterações filosóficas. Surge uma das mais importantes criações da Modernidade: a figura do "indivíduo", sujeito de

\footnotetext{
${ }^{1}$ A pesquisa a que se refere esta comunicação integra o processo que visa à obtenção do título de dout orado.

${ }^{2}$ Modo de indicar o avanço tecnológico no Estado que é tomado por transformações com o seu advento.
} 
direitos, "dono do próprio destino" dentro de uma concepção liberal de humanidade, extensiva e abstrata. Constitui-se o Estado Moderno (NUNES, 2007, p. 100).

O Estado moderno se estabelece na revolução tecnológica e entendemos que nesse contexto a sociedade indica o desprendimento da religiosidade, pois estabelece parâmetros científicos e da razão como prioritários. Segundo Maria José Rosado Nunes (2007, p.101), o pensamento mítico-religioso é pouco a pouco substituído pelo cálculo racional do pensamento das luzes.

No entanto, o sujeito da revolução tecnológica que emigra vê no novo país, em meio às mudanças e adaptação que ressalta a dificuldade da distância familiar, a igreja como espaço que minimiza suas dificuldades, sobretudo as emocionais. Chiara Pussetti, pesquisadora Associada Sénior do Centro em Rede de Investigação em Antropologia (CRIA), realizou uma pesquisa de terreno por quatro anos sobre a saúde mental de imigrantes em Portugal e concluiu que as condições particularmente duras da migração contemporânea são consideradas como propícias a um aumento exponencial de psicopatologias. Não verificamos pesquisas dessa natureza em Orlando, mas nas entrevistas que realizamos, rotineiramente foram relatados pelos entrevistados problemas emocionais vivenciados durante a trajetória migratória. São esses problemas indicados por eles, por consequência da distância familiar, frustrações e medos diante da incerteza no cotidiano e, principalmente, quando estão no país de modo ilegal ou sem status. Esse tema não foi abordado nas entrevistas, mas relatado pelos entrevistados enquanto discursavam sobre sua trajetória de imigrante.

Quanto às Igrejas, percebemos que há uma estrutura organizacional frente ao fluxo migratório: disponibiliza a interculturalidade, apoio migratório, reconfiguração familiar e experiência com o sagrado. Percebemos que as transformações do Estado Moderno comunicam o advento da nova Empresa religiosa ${ }^{3}$, pois há uma nova configuração dos objetivos de alcance de novos fiéis,

\footnotetext{
${ }^{3}$ Utilizamos o termo Empresa porque as instituições religiosas se estabelecem na Flórida Central como Empresa aberta, mas com isenção de impostos. Utilizamos esse termo por constituir sua função oficial no Estado.
} 
sobretudo ao imigrante que se estabelece no novo país com muitas incertezas e medo da frustração do seu sonho de "fazer a América"4.

É importante ressaltar que as Empresas religiosas desenvolvem considerável trabalho de apoio aos imigrantes brasileiros e, por este motivo, percebemos a importância de verificar como funciona o seu trabalho social e religioso para os brasileiros na Flórida Central. "Se anteriormente eram os missionários estrangeiros que vinham para o Brasil acompanhando os imigrantes, a partir dos anos 8o são os missionários brasileiros que saem pelo mundo seguindo os fluxos dos emigrantes do país.” (MARTES, 1999, p. 113).

Ana Cristina Braga Martes realizou sua tese de doutorado sobre os imigrantes brasileiros em Massachusetts e, no capítulo que destina às igrejas, indica o rápido crescimento das igrejas brasileiras, especialmente as evangélicas. Ela diz que até 1993 eram contabilizadas trinta igrejas cristãs brasileiras no estado e fornece uma tabela com o survey realizado com 300 pessoas durante sua pesquisa.

Imagem 1: Tabela do survey da Ana Cristina Braga Martes

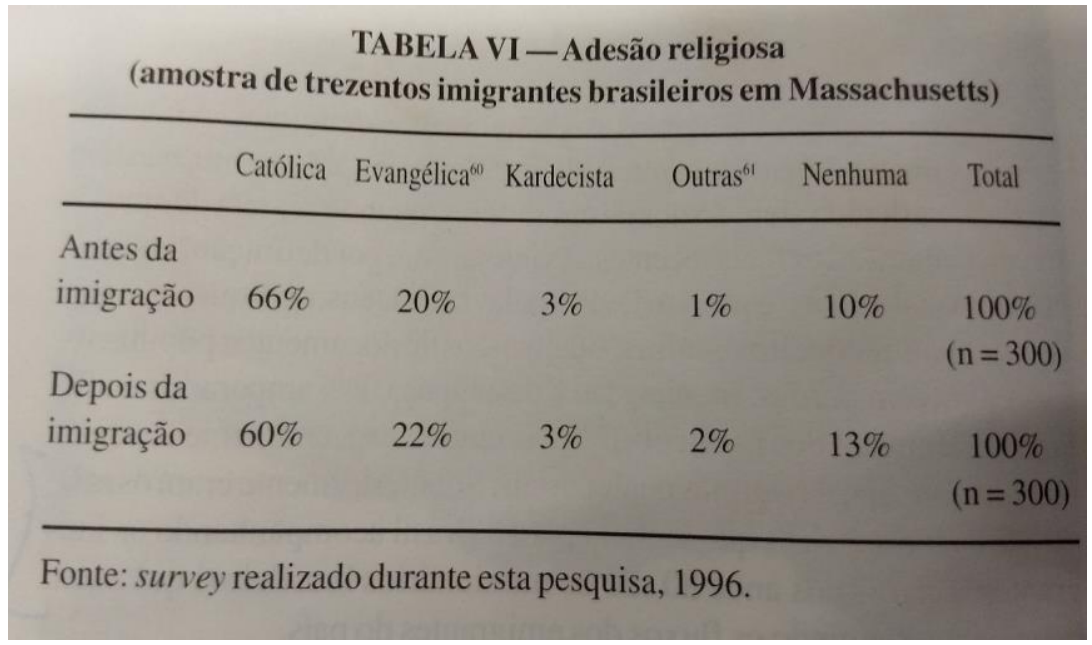

Fonte: Martes (1999).

\footnotetext{
${ }^{4}$ Termo usado pelos brasileiros que decidem emigrar. Usualmente também é utilizado o "sonho da América" ou, quando já imigrante, "fazendo a América".
} 
Os dados apresentados nas tabelas apenas reafirmam aquilo que qualquer contato mais superficial com os brasileiros em Massachusetts já seria suficiente para reconhecer: o número de evangélicos naquele estado é superior ao encontrado no Brasil (13\%). A presença das igrejas evangélicas entre os brasileiros é, na verdade, uma das características mais visíveis deste movimento migratório. (MARTES, 1999, p. 115).

Em Orlando, temos mais de setenta e cinco igrejas brasileiras cristãs registradas. Do total, apenas uma igreja católica é totalmente voltada aos brasileiros e nas demais igrejas católicas americanas existem pequenos grupos de brasileiros e, em alguns casos, tradução simultânea. Com base no levantamento dos registros atuais e survey que estamos realizando em Orlando, há atualmente pelo menos 75 denominações protestantes com atividades brasileiras.

No survey em andamento, atualmente com participação de 178 pessoas, decidimos estruturá-lo de modo a definir os dados sociodemográficos dos brasileiros em Orlando com foco na identificação do fluxo migratório nas igrejas. Decidimos não perguntar qual religião, mas "qual igreja frequenta em Orlando", visto que com essa resposta temos acesso ao dado sobre religião e o dado das igrejas escolhidas pelos brasileiros. O nosso interesse também é o de identificar possíveis denominações religiosas que não estão registradas. Destaque-se que essa adaptação na coleta nos ajudará a conhecer e caracterizar as denominações religiosas com participação de imigrantes brasileiros, como também verificar as características motivacionais para a crescente implantação de novas igrejas evangélicas, as que chamamos de igrejas da modernidade.

Nas pesquisas até o momento, percebemos que há dois campos religiosos com maior trabalho e escolha dos imigrantes: 1) igreja evangélicas, englobando nessa identificação aos protestantes tradicionais e pentecostais; 2) Igreja Católica Apostólica Romana. Até o momento apenas essas foram citadas no survey e aguardamos ao final a possível indicação do 3) Religiões Afro e outros. 
Tabela 1 - percentual de "NFIO" e "FIO"

(Amostra de 178 imigrantes brasileiros em Orlando)

$$
\begin{gathered}
\text { NFIO }-34,83 \% \\
\text { FIO }-65,17 \%
\end{gathered}
$$

Fonte: Survey realizado durante a pesquisa, em 2019.

Na tabela, indicamos "Não frequenta Igreja em Orlando" com a sigla: NFIO e "Frequenta Igreja em Orlando" com a sigla: FIO. Na tabela posterior, indicamos as sete igrejas mais citadas pelos participantes no survey e percebemos que do total (38 - trinta e oito igrejas), muitas não estão indicadas nos registros atuais do consulado ou revista Gospel da cidade. Pretendemos, ao final do survey, fazer o levantamento e registro de todas as igrejas indicadas, adicionando a informação sobre as igrejas não mencionadas nos dados oficiais da cidade.

Tabela 2 - Igrejas mais citadas 71 pessoas de 116 ao total dos FIO

$$
\begin{array}{cc}
\text { ICAR }-18,35 \% & \text { BATISTA }-5,5 \% \\
\text { FBCO }-18,35 \% & \text { FBCW }-4,5 \% \\
\text { LAGOINHA - 13,7\% } & \text { GFC }-4,5 \% \\
\text { MSBN }-7,3 \% &
\end{array}
$$

Fonte: Survey realizado durante esta pesquisa, 2019.

Para nossa leitura, identificamos a Igreja Católica Apostólica Romana com a abreviatura ICAR; First Baptist Orlando para FBCO; Lagoinha Orlando Church para LAGOINHA; Ministério Semeadores de Boas Novas para MSBN; First Baptist Church Windermere para FBCW; Graça Fellowship Church para GFC; Batista para BATISTA. Nesta tabela, inserimos as Igrejas que foram indicadas cinco ou mais vezes. No total, até o momento 38 (trinta e oito) igrejas foram citadas no survey. 
Acima estão as sete igrejas que mais têm notoriedade em Orlando, vale salientar que esse primeiro levantamento confirma os dados que encontramos nas entrevistas "corpo a corpo" que evidenciava a Igreja Católica e Igreja Batista com mais visibilidade entre os brasileiros na Central Flórida.

É interessante perceber a quantidade de igrejas citadas que não fazem parte dos registros que atualmente temos como referência sobre as igrejas. Ademais, percebemos que a maioria frequenta igrejas "brasileiras" e identificamos esse termo "igrejas brasileiras" associado às que mantêm cultos e trabalhos religiosos específicos para a comunidade brasileira, como também as propriamente brasileiras e com fundação de brasileiros em Orlando, que é o caso do MSBN.

Outro dado interessante é a quantidade de igrejas batistas "separadas". Temos First Baptist Orlando, First Bapstis Windermere, Igreja Batista Atitude, Igreja Batista Central Flórida, Primeira Igreja Batista Brasileira de Orlando, temos a própria Lagoinha, que também é Batista e inserimos a "Batista” porque foi citada desta forma no survey, possivelmente um modo de não se identificar totalmente na pesquisa.

Não é difícil perceber que muitas igrejas cristãs identificadas como evangélicas, buscam consolidação cada vez mais autônomas; o exemplo das "batistas" marca na cidade de Orlando os novos protestos religiosos5 que atribuem crescente ampliação de denominações cristãs. Na Igreja católica há uma centralidade hierárquica que não se verifica nas outras denominações citadas. É importante ressaltar também que as igrejas se estabelecem primeiramente como empresas abertas na América, são isentas de impostos e desenvolvem suas atividades religiosas e sociais. No entanto, causa estranheza a quantidade de denominações que surgem em contraponto às suas origens. Perceber que há para a denominação Batista tamanha diversidade numa mesma cidade chama bastante

\footnotetext{
${ }^{5}$ Referência ao protesto de Martin Lutero que marca oficialmente a diversidade religiosa cristã, formando as denominações conhecidas como evangélicas ou protestantes.
} 
atenção; até agora, o conjunto das igrejas batistas tem o maior número de adeptos em Orlando.

Em Massachusetts, de acordo com a pesquisa realizada por Martes (1996), a igreja com mais adeptos e, portanto, mais conhecida é a Assembleia de Deus. A autora acrescenta um dado relativo à sua experiência no campo e define uma identidade religiosa de recrutamento que difere do que encontramos em Orlando.

\begin{abstract}
Apenas para citar um fato curioso, quando fui entrevistar o pastor, ele pediu que lhe cedesse dez minutos para "falar comigo sobre Deus". Em seguida, tentou me sensibilizar para uma possível conversão por meio de dois artifícios. O primeiro foi tentar despertar em mim um sentimento de culpa ("você está tendo neste momento uma chance em sua vida que será lembrada por Deus no dia do Juízo Final”). O segundo foi o de oferecer "segurança da igreja" à minha família, especialmente ao meu filho ("Nesta igreja seu filho estará a salvo das drogas, deste mundo cada vez mais perigoso"). Estes dois pontos (a ameaça do inferno e a segurança da família) são usados sistemática e recorrentemente como recursos para os processos de conversão em geral. (MARTES, 1999 p. 125).
\end{abstract}

$\mathrm{Na}$ nossa experiência com as coletas de dados nas igrejas e mais efetivamente no MSBN, que é uma “célula" da Assembleia de Deus, a partir de entrevistas e pesquisa participante em cultos e eventos da igreja, não houve convite para “conversão" e essa foi uma característica que trouxe curiosidade, visto que apenas ao final das entrevistas ocorria o convite para participar de culto ou, no caso da Igreja Católica, para participar da missa.

Tentando entender a razão desse comportamento, percebemos na experiência com o campo que atualmente a forma de recrutamento ocorre principalmente por meio das ajudas que as igrejas oferecem. Exemplificando, caso eu precisasse de alguma coisa que a igreja pudesse oferecer, como indicação de escola para meu filho, ou informações em relação à saúde e qualquer situação de dificuldade na cidade, eu poderia acionar a igreja, que encontraria auxílio. Essa foi a declaração feita pela liderança das igrejas e reafirmada pelos fiéis, e esse comportamento dos líderes das igrejas é o que mais alcança a atenção e conversão dos imigrantes em Orlando. 
Percebemos que atualmente os "artifícios" apontados pela pesquisadora em Massachusetts aos poucos se mostram ineficazes, o que demonstra a modernização das denominações religiosas que, em Orlando, enfrentam o advento da crise das religiões com ressignificação de suas atividades. Como já indicamos, a ajuda pessoal e social antecede a experiência religiosa.

Ressaltamos também que as sete igrejas mais citadas no nosso survey, o qual se encontra aberto, mantêm atividades específicas para brasileiros, o que demonstra o vínculo dos imigrantes a uma religiosidade cultural brasileira e quando inseridos em igrejas que não mantêm cultos, missas e atividades no idioma brasileiro, buscam a inserção de tradução simultânea. Nas igrejas brasileiras ou que mantêm atividades específicas para brasileiros, como é o caso do MSBN, Ministério Semeadores de Boas Novas, ocorre uma inversão da tradução simultânea que, neste sentido, é para o inglês americano.

Quanto aos dados sociodemográficos, obtivemos no site oficial do censo dos Estados Unidos - Census/American Community Survey -, no programa oficial de estimativa populacional de 2017, os dados gerais sobre a população brasileira na Flórida, estimados em 109, 688 mil pessoas. Em percentual, verificamos que 57,1\% se constitui de mulheres e $42,9 \%$ de homens. Quanto à idade, $26 \%$ tem idade entre 35 a 44 anos, 20, 2 \%, idade entre 45 a 54 anos e $16,9 \%$, idade entre 25 a 34 anos. Esses são os três maiores percentuais apresentados e o menor é o de crianças abaixo de 5 anos com apenas 1,8 \%. Salienta-se que o percentual de casados alcança o número de $65,1 \%$, e o de divorciados, apenas $9,5 \%$.

No survey, percebemos um percentual semelhante ao encontrado nos dados oficiais para a Flórida. As mulheres constituem 70,22\%, enquanto homens 29,78 \%. Quanto à idade, 62,36 \% constitui idade de 20 a 44 anos; 37,08\% com 45 anos ou mais e $0,56 \%$ com idade até 19 . Quando perguntados sobre a região de origem no Brasil, o Sudeste é a região com maior percentual, pois chega a 57,63\%, seguindo de um percentual com 18,08\% do nordeste, $12,43 \%$ do sul, 7,34\% do centro-oeste e $4,52 \%$ do norte. 
Indicamos também percentual dos dados sobre o grau de escolaridade, o qual chama bastante atenção, pois o maior percentual é de 38, 76\% para superior completo; segundo maior com 29,78\% com pós-graduação; em seguida 12, 92\% com superior incompleto; 12,36\% com ensino médio completo; 5,06\% com curso técnico e 1,12\% com ensino médio incompleto. Dessa forma, o perfil de escolaridade dos imigrantes brasileiros em Orlando indica pessoas com grau superior de qualificação.

Esses dados representam nossa primeira verificação da coleta online, que disponibilizamos na plataforma SurveyMonkey, sobre os dados sociodemográficos de brasileiros em Orlando com participação de 178 (de cento e setenta e oito) pessoas.

Segundo dados do Consulado geral do Brasil em Miami, cerca de 300 mil brasileiros residem na Flórida. Esse número é uma estimativa que não alcança a totalidade, já que não são contabilizados os imigrantes que vivem ilegalmente no Estado. As pesquisas revelam que brasileiros deixam o país em busca de condição mais favorável de vida e muitos deles se desapegam de funções de prestígio e simplesmente aceitam trabalhos mais exaustivos. Entendemos que a razão principal seria que eles preferem trabalhos que no Brasil não são de prestígio, mas que nos Estados Unidos garantem a sobrevivência com qualidade de vida. Acontece de encontrarmos pessoas que simplesmente largaram estabilidade financeira para a "aventura" do dia após dia entre helper de "housekeeping ou bricks". Encontramos relatos de que a garantia da segurança vale a exaustão das, no mínimo, doze horas diárias de trabalho.

Temos brasileiros que insistem em rotinas heroicas com trabalhos que exigem muito esforço, dizem eles, destinados à garantia de uma vida melhor para os filhos. Ouvimos muito o "eu prefiro me submeter ao trabalho pesado e garantir um futuro melhor para meus filhos". As falas podem ser lidas como uma idealização de um projeto que indica alcançar grande êxito, afinal, "aos cinco anos, as crianças são incluídas no sistema educacional da maior potência do mundo”. 
Costumamos dizer que Orlando é um "centro brasileiro", pois encontramos muitos brasileiros como turistas e como residentes. É importante situar que o Brasil está no ranking dos principais países que fazem investimento e expansão de negócios da América Latina. Está na lista das "Sister Cities" com representação principal de Curitiba. A prefeitura de Orlando cita Curitiba como cidade "semelhante a Orlando" e busca seu exemplo no funcionamento do transporte público, visto que a quantidade de carros é expressiva em Orlando porque não há um funcionamento de transporte público, apesar de que esse grande fluxo não interfere no bom andamento do trânsito. Mesmo assim, as declarações do comissário Fernando Ortiz, na página da prefeitura de Orlando, indicam uma surpresa com o funcionamento do transporte público em Curitiba.

A capital do Estado sulista do Paraná, Curitiba, foi designada como Centro Ambiental do MERCOSUL e Capital de Software do Brasil. "Curitiba é um ótimo exemplo de uma cidade que adotou o planejamento urbano e sistemas de transporte abrangentes. Com líderes visionários e força de trabalho criativa e diligente, Curitiba tem muito em comum com Orlando, incluindo um parque central com barcos de cisne." 6

A prefeitura se fez presente em Curitiba a partir do comissário de Orlando, Fernando Ortiz, que passou a semana diplomática, entre 19 e 26 de junho de 2018, com o objetivo de buscar negócios para ambas as cidades e trocar ideias sobre o transporte público. Essa oportunidade reafirmou a relação de "Sister City" que surgiu em 1996 entre a capital do Paraná, Curitiba, que é uma das nove cidades irmãs de Orlando. A partir do evento, Ortiz falou sobre Curitiba, que representa o Brasil para Orlando com ênfase no empreendedorismo de produtos ecológicos que gera uma economia sustentável e ficou impressionado "com as 120 organizações de empreendedorismo social de Curitiba, que ajudam pessoas em necessidade, enquanto tratam de questões ambientais.” Diz ainda Ortiz:

\footnotetext{
${ }^{6}$ Informação no "City of Orlando" site oficial da prefeitura de Orlando.
} 
Os benefícios que esses produtos surpreendentes e inovadores podem trazer para nossa cidade vão além da economia", disse Ortiz. "À medida que continuamos a crescer como líderes mundiais, o uso responsável de alternativas sustentáveis não é mais uma opção, mas um dever vital. (Ortiz in City of Orlando).

A relação entre Curitiba e Orlando é a de "sister" e percebemos essa apropriação do termo com integração e familiaridade brasileira por toda parte de Orlando. As nove cidades irmãs de Orlando, e as respectivas datas em que se estabeleceu tal relação, são:

\begin{tabular}{|l|l|}
\hline Curitiba, Brasil & 1996 \\
\hline Guilin, China & 1986 \\
\hline Seine-et-Marne, França & 1991 \\
\hline Reykjanesbaer, Islândia & 1991 \\
\hline Urayasu, Japão & 1989 \\
\hline Monterrey, México & 1995 \\
\hline Orenburg, Rússia & 1997 \\
\hline
\end{tabular}

Para termos ideia, o Brasil está na primeira posição do ranking de principais parceiros de comércio de mercadorias da Flórida, que é o quarto Estado que mais exporta dos Estados Unidos, ficando atrás de Texas, Califórnia e Nova York. No ranking de principais parceiros estão, em ordem de importância: Brasil, Colômbia, China, Japão, Suíça, Venezuela, Chile, costa rica, República Dominicana e México. ${ }^{7}$

Essa relação "sister" confirma provavelmente a familiaridade que o brasileiro tem com Orlando, pois muitos deles arriscam viver na cidade "sem status" ou "ilegalmente" em busca de segurança, estabilidade financeira, em suma, de qualidade de vida. Causa certa estranheza, entretanto, saber que a escolha por migrar não se dá apenas pela busca de estabilidade financeira. Certamente, algumas motivações que definem as gerações migratórias são facilmente visíveis:

\footnotetext{
${ }^{7}$ Todos os dados são do site oficial da City of Orlando entre artigos e Orlando City Council Workshop Presentation.
} 
fugir da crise econômica e da insegurança e buscar mais qualidade de vida. Todavia, nas razões da diáspora brasileira encontram-se também os sonhos de estudar fora do país ou simplesmente de idealização da vida americana tomada como perfeita. Chamamos esses de "influenciados por Hollywood", que é uma parcela significativa de brasileiros fascinados pelo que idealizaram a partir do marketing midiático em favor da cultura americana.

A princípio, tivemos conhecimento da realidade migratória, na prática, a partir de familiares residentes. Sabendo de todas as dificuldades, percebemos em paralelo quão forte é a efervescência religiosa entre os imigrantes e buscamos a viabilidade de discussões atuais sobre os problemas migratórios, assim como a estrutura religiosa brasileira na América do século XXI.

Esses dados estão inseridos em contextos sociais, políticos, econômicos e religiosos que revelam a relevância teórica multidisciplinar para o atual debate acadêmico, como também com contribuição informacional de credibilidade para o sujeito do fluxo migratório e atualização histórica de registros das igrejas brasileiras em Orlando.

\section{Considerações finais}

A motivação para esta pesquisa surgiu a partir do interesse de entender a importância da igreja para o imigrante brasileiro. O Brasil enfrenta grandes problemas no sistema político que desencadeia consequências econômicas negativas para a sociedade brasileira e, principalmente, para a população mais carente. Com essas dificuldades latentes, muitos brasileiros encontram na imigração uma saída e idealizam os Estados Unidos como o país que oferece "qualidade de vida".

Os dados indicados constituem-se a partir de uma pesquisa de campo em andamento no estado da Flórida, mais especificamente na cidade de Orlando. Contamos com auxílio de entrevistas estruturadas, plataforma monkeysurvey, pesquisa participante e indicamos que utilizamos de uma "metodologia intuitiva" 
pois o campo revela um "receio de ser visto, principalmente porque grande percentual é constituído de sujeitos não documentados. Buscamos explorar de intuição e certa criatividade para alcançá-los e deixá-los confortável para fornecimento de seus dados.

Percebemos que o perfil migratório indica muitas questões inexploradas, a realidade do "apoio das igrejas", por exemplo, precisa ser conhecida e abordada para que o sujeito imigrante conheça adequadamente sua função e ao chegar no novo país tenha previamente o conhecimento adequado sobre o fluxo migratório, o nosso intuito é sobretudo contribuir com a informação atualizada sobre a migração considerando, pois, que muitos brasileiros não conhecem adequadamente a realidade migratória. Esta pesquisa, como dito, encontra-se em andamento.

\section{REFERÊNCIAS}

AGÊNCIA BRASIL. Perfil de empreendedores brasileiros no exterior. Rio de Janeiro, 2014. Disponível em: <http://agenciabrasil.ebc.com.br/economia/noticia/2014-o8/pesquisada-uff-traca-perfil-de-empreendedores-brasileiros-no-exterior >. Acesso em: 20 abr. 2019.

APPEL, John; APPEL, Selma. Comics da imigração na América. São Paulo: Perspectiva, 1994.

ASSIS, Gláucia de Oliveira. "De Criciúma para o mundo" - Os novos fluxos da população brasileira: gênero e rearranjos familiares. In: MARTES, Ana Cristina Braga;

FLEISHCHER, Soraya (org.). Fronteiras cruzadas: etnicidade, gênero e redes sociais. São Paulo: Paz e Terra, 2003. p. 199-230.

BESERRA, Bernadete. Brasileiros nos Estados Unidos: Hollywood e outros sonhos. Fortaleza: UFC; São Paulo: HUCITEC; Santa Cruz: UNISC, 2005.

BRAZILIAN TIMES. Padre Volmar Scaravelli vai receber prêmio da MAPS. 12/2016. Disponível em: https://www.braziliantimes.com/comunidadebrasileira/2016/12/21/padre-volmar-scaravelli-vai-receber-prmio-da-maps.html. Acesso em: 20 abr. 2019.

BRAZILUSA. Confraternização da AME e brasileiras em Orlando. 26/12/2017. Disponível em: http://www.brazilusamagazine.com/article/confraternizacao-da-ame/. Acesso em: 19 abr. 2019.

BRAZILUSA. Doutoranda faz pesquisa sobre a experiência religiosa de brasileiros nos Estados Unidos. BrazilUSA. Ed 21. 01/2019. p. 16. 
BRAZILUSA. Pastora Rita há 10 anos como presidente do Conselho dos Pastores de Orlando. 28/02/2018. Disponível em:

http://www.brazilusamagazine.com/article/pastora-rita-ha-10-anos/. Acesso em: 18 abr. 2019.

COMUNIDADE CATÓLICA BRASILEIRA DE ORLANDO. Ressurrection Catholic Church, 2019. Disponível em: https://www.catolicosemorlando.com/about. Acesso em: 18 abr. 2019.

CONSULADO GERAL DO BRASIL EM MIAMI. Mapeamento comunidade brasileira na Flórida. Disponível em: http://miami.itamaraty.gov.br/pt-br/comunidade_brasileira.xml. Acesso em: 18 abr. 2019.

CRUZ, Eduardo Picanço; FALCÃO, Roberto Pessoa de Queiroz; BARRETO, Cesar Ramos. Estudo exploratório do empreendedorismo imigrante brasileiro em Pompano Beach e Orlando - EUA. Revista Gestão e Planejamento, Salvador, v. 18, p. 37-54, jan./dez. 2017.

CSEM - Centro Scalabriniano de estudos migratórios, 2019. Disponível em: https://www.csem.org.br/institucional/. Acesso em: 20 abr. 2019. Acesso em: 18 abr. 2019.

DEBIAGGI, Sylvia Dantas. Famílias brasileiras em um novo contexto cultural. In: MARTES, Ana Cristina Braga; FLEISHCHER, Soraya (org.). Fronteiras cruzadas: etnicidade, gênero e redes sociais. São Paulo: Paz e Terra, 2003. p. 175-198.

DIAS, Eduardo. Um imigrante e a evolução: memórias de um militante operário 19341951. São Paulo: Brasiliense, 1983.

DIOCESE OF ORLANDO. About the Diocese. 2019. Disponível em: https://www.orlandodiocese.org/our-diocese/our-diocese-about-us/. Acesso em: 20 abr. 2019.

FIRST BAPTIST ORLANDO. About the Brazilian ministry. 2019. Disponível em: https://www.firstorlando.com/. Acesso em: 20 abr. 2019.

HALTER, M. New migrants in the Marketplace: Boston's ethnic entrepreneus. Amherst: University of Massachusetts Press, 1995.

JESUS, Sonia Melo de. Protagonistas de um Brasil imaginário: faxineiras brasileiras em Boston. In: MARTES, Ana Cristina Braga; FLEISHCHER, Soraya (org.). Fronteiras cruzadas: etnicidade, gênero e redes sociais. São Paulo: Paz e Terra, 2003.

MARGOLIS, Maxine L. Goodbye Brazil: emigrantes brasileiros no mundo. São Paulo: Contexto, 2013.

MARGOLIS, Maxine L. Little Brazil: imigrantes brasileiros em Nova York. Campinas: Papirus, 1994. 
MARGOLIS, Maxine L. Na virada do milênio: a emigração brasileira para os Estados Unidos. In: MARTES, Ana Cristina Braga; FLEISHCHER, Soraya (org.). Fronteiras cruzadas: etnicidade, gênero e redes sociais. São Paulo: Paz e Terra, 2003. p. 51-72.

MARTES, Ana Cristina Braga. Brasileiros nos Estados Unidos: um estudo sobre imigrantes em Massachusetts. São Paulo: Paz e Terra, 1999.

MARTES, Ana Cristina Braga. Os imigrantes brasileiros e as igrejas em massachusetts. In: REIS, Rossana Rocha; SALES, Teresa (org.). Cenas do Brasil Migrante. São Paulo: Boitempo, 1991.

MARTES, Ana Cristina Braga. Raça e etnicidade - opções e constrangimentos. In: MARTES, Ana Cristina Braga; FLEISHCHER, Soraya (org.). Fronteiras cruzadas: etnicidade, gênero e redes sociais. São Paulo: Paz e Terra, 2003. p. 73-98.

MARTES, Ana Cristina Braga; FLEISHCHER, Soraya (org.). Fronteiras cruzadas: etnicidade, gênero e redes sociais. São Paulo: Paz e Terra, 2003.

MENEZES, Gustavo Hamilton. Filhos da imigração: a segunda geração de brasileiros em Connecticut. In: MARTES, Ana Cristina Braga; FLEISHCHER, Soraya (org.). Fronteiras cruzadas: etnicidade, gênero e redes sociais. São Paulo: Paz e Terra, 2003. p. 157-198.

MITCHELL, Christopher. Perspectiva comparada sobre transnacionalismo entre imigrantes brasileiros nos Estados Unidos. In: MARTES, Ana Cristina Braga; FLEISHCHER, Soraya (org.). Fronteiras cruzadas: etnicidade, gênero e redes sociais. São Paulo: Paz e Terra, 2003. p. 33-50.

MSBN CHURCH. Orlando Campus. 2019. Disponível em: http://www.semeadores.com/. Acesso em: 20 abr. 2019.

MULHER BRAZILUSA. Pastora Renata Loyolla: é um privilégio servir a comunidade, 2018. Disponível em: https://mulherbrazilusa.com/pastora-renata-loyolla-e-um-privilegio-servir-acomunidade/. Acesso em: 20 abr. 2019.

MULHER BRAZILUSA. Revista Vencedoras 2017. Disponível em: https://mulherbrazilusa.com/revista-vencedoras-2017/. Acesso em: 20 abr. 2019.

NASCIMENTO, Kelly Thaysy Lopes. O caminho da educação. Real Estate BrazilUSA, 12/2018. p. 20.

NOSSA GENTE. Entenda relação do brasileiro com religião na Central Florida. n. 142, 15/2019. p. 17.

NOSSA GENTE. Pra. Rita confessa seu amor por Orlando. Ed. o8/2008, p. 18.

NOSSA GENTE. Trabalho humanitário apoia famílias que chegam a Orlando. Ed. 09/2017, p. 19. 
NUNES, Maria José Rosado. A sociologia da religião. In: USARSKI, Frank (org.). O espectro disciplinar da Ciência da Religião. São Paulo: Paulinas, 2007. p. 97-120.

OLIVEIRA, Adriana Capuano de. O caminho sem volta - classe social e etnicidade entre os brasileiros na Flórida. In: MARTES, Ana Cristina Braga; FLEISHCHER, Soraya (org.).

Fronteiras cruzadas: etnicidade, gênero e redes sociais. São Paulo: Paz e Terra, 2003. p. $115-138$.

PIBBORLANDO CHURCH. Quem somos. 2019. Disponível em: < https://www.pibborlando.org/quem-somos-2/>

REIS, Rossana Rocha; SALES, Teresa (org.). Cenas do Brasil migrante. São Paulo: Boitempo, 1991.

RESENDE, Rosana. Brasileiros no sul da Flórida - relatos de uma pesquisa em andamento. In: MARTES, Ana Cristina Braga; FLEISHCHER, Soraya (org.). Fronteiras cruzadas: etnicidade, gênero e redes sociais. São Paulo: Paz e Terra, 2003. p. 139 -156.

ROCHA, Cristina; VÁSQUEZ, Manuel A. (org.). A diáspora das religiões brasileiras. São Paulo: Ideias e Letras, 2016.

SALES, T.; LOUREIRO, M. Imigrantes brasileiros adolescentes e de segunda geração em Massachusetts, EUA. Revista Brasileira de Estudos de População, Campinas, v. 21, n. 2, p. 217-239, jul./dez. 2004.

SALES, Teresa. A organização dos imigrantes brasileiros em Boston, EUA. São Paulo em Perspectiva, São Paulo, v. 19, n. 3, p. 44-54, 2005. Disponível em:

http://www.scielo.br/scielo.php?script=sci_arttext\&pid=S0102-88392005000300004. Acesso em: Acesso em: 18 abr. 2019.

SALES, Teresa. Brasil migrante, Brasil clandestino. São Paulo em Perspectiva, São Paulo, v. 8, n. 1, p. 107-115, 1994.

SALES, Teresa. Brasileiros longe de casa. São Paulo: Cortez, 1999.

SEMINÁRIO CONGREGACIONAL DA PASTORAL DAS MIGRAÇÕES. Expressão de um Carisma a serviço dos Migrantes: III Seminário Congregacional da Pastoral das Migrações/CSEM. Brasília: CSEM, 2006.

TEIXEIRA, Paulo Eduardo; BRAGA, Antonio Mendes da Costa; BAENINGER, Rosana (org.). Migrações: implicações passadas, presentes e futuras. São Paulo: Cultura Acadêmica, 2012.

UNITED STATES CENSUS BUREAL. Survey of Business Owners (SBO) - Characteristics of Businesses: 2007. January, 2007. 